\title{
PKHD1 Geni Yanlış Anlam Mutasyonları Kedilerde Sebebi Bilinmeyen Böbrek Hastalıkları İçin Önemli Olabilir mi?
}

\author{
Nüket BíLGEN ${ }^{1, a, *}$ \\ ${ }^{1}$ Ankara Üniversitesi, Veteriner Fakültesi, Genetik Anabilim Dalı, Ankara, Türkiye \\ aORCID: 0000-0003-2324-7965
}

Geliş Tarihi: 18.08.2021

Kabul Tarihi: 27.10.2021

\begin{abstract}
Özet: Polikistik böbrek hastalığı (PKD), insanlarda otozomal resesif ve otozomal dominant olarak görülen heterojenik arka planı olan genetik bir hastalıktır. Kedilerde otozomal dominant PKD sıklıkla rapor edilirken, otozomal resesif PKD bildirilmemiştir. Tüm genom dizilemesi yapılmış olan siyam ırkı bir erkek kedide biyoinformatik analizler sonucunda PKHD1 geninde çeşitli yanlış anlam mutasyonları tespit edilmiştir. Bu Siyam ırkı kedinin kastrasyon için özel bir veteriner kliniğine getirilmesinin ardından böbrek ve karaciğeri izlemek için geniş kan paneli yapıldı ve yüksek BUN ve kreatinin değerleri gözlendi. Ayrıca GPT değerinin de 2,5 kat olduğu belirlendi. Kedilerde nadiren PKD1 mutasyonundan bağımsız kistik böbrek vakaları bildirilmektedir. Ancak otozomal çekinik polikistik böbrek hastalığına neden olan genler için kedi genomları daha önce incelenmemiştir. Bu çalışmada kedi genom verilerinde $(n=100)$ otozomal resesif PKD'ye neden olan PKHD1 geni incelenmiştir. İnceleme sonucunda SIFT skoru yüksek 4 farklı mutasyon belirlenmiş ve bu mutasyonların PKHD1 geninden üretilen 7 transkriptte dur kodonu oluşumu ve dur kodonu kaybı ile sonuçlandığı ortaya konmuştur. Nadir hastalık olmasını destekler nitelikte, belirlenen mutasyonların frekanslarının $0.003,0.001,0.001$ ve 0.003 olduğu hesaplanmıştır.
\end{abstract}

Anahtar kelimeler: Böbrek, Kedi, genom, PKHD1 geni

\section{Could PKHD1 Gene Missense Mutations Be İmportant for İdiopathic Kidney Disease in Cats?}

Abstract: Polycystic kidney disease (PKD) is a genetic disease with a heterogeneous background seen in humans as autosomal recessive and autosomal dominant. While autosomal dominant PKD is frequently reported in cats, autosomal recessive PKD has not been reported. Various missense mutations in the PKHD1 gene were detected as a result of bioinformatic analyzes in a male cat whose whole genome was sequenced. After this Siamese cat was brought to a private veterinary clinic for castration, a broad blood panel was performed to monitor kidney and liver, and elevated BUN and creatinine values were observed. In addition, the GPT value was determined to be 2.5 times higher. Cases of cystic kidney independent of PKD1 mutation have been reported rarely in cats. However, cat genomes have not been previously examined for genes that cause autosomal recessive polycystic kidney disease. In this study, the PKHD1 gene, which causes autosomal recessive PKD, was examined in cat genome data $(n=100)$. As a result of the examination, four different mutations with high SIFT scores were identified. These mutations resulted in stop codon formation and loss of stop codons in 7 transcripts produced from the PKHD1 gene. The frequencies of the determined mutations were calculated to be 0.003 , $0.001,0.001$, and 0.003 , which supports the fact that it is a rare disease.

Keywords: Cat, Genome, Kidney, PKHD1 gene.

\section{Giriş}

Böbrek yetmezliği kedilerde en sık görülen ve özellikle de ileri yaşlı kedilerde ölümle sonuçlanabilen ya da ötenazi gerektirebilen bir hastalıktır. Özellikle Kronik Böbrek Hastalıkları görülme sıklığı kedinin ırkına da bağlı olarak \%1,6-20 arasında değişmektedir (Chen ve ark., 2020). Kedilerde böbrek yetmezliği genetik kökenli ve çevresel nedenlere bağlı olarak gözlenebilmektedir (Gardner, 1988).

Insanlarda genetik heterojeniteye sahip polikistik böbrek hastalığı (Polycystic Kidney Disease, PKD) hastalığı sıvı taşınması ve kemo- ve mekanik sensöriyal işlevi gören mikrotübül bazlı bir organel olan silyaların oluşumunda veya yapısında yer alan genlerde meydana gelen mutasyonlar ile ilişkilendirilmiştir (Bilgen ve ark., 2020). Bu mutasyonlardan Polisistin-1 (PKD1), polisistin-2 (PKD2), nötral alfa-glukosidaz $\mathrm{AB}$ (GANAB, PKD3) ve DnaJ homolog alt ailesi B üyesi 11 (DNAJB11, PKD6) genlerinde olanlar otozomal dominant PKD ile ilişkilendirilmiştir. Fibrosistin (PKHD1, PKD4) ve çinko parmak proteini DZIP1L (DZIP1L, PKD5) genlerinde bulunan mutasyonlar ise hastalığın otozomal resesif versiyonu ile ilişkilendirilmiştir. Kedilerde Polisistin 1 (PKD1) geninde meydana gelen bir nokta mutasyonu protein dizisinde erken sonlanmaya neden olmaktadır ve bu mutasyon kedilerde otozomal dominant polikistik böbrek hastalığı ile sonuçlanmaktadır (Lyons ve ark., 2004). Özellikle genç yaştaki kedilerde sıklıkla görülen 
kronik böbrek yetmezliklerinin nedeni sadece PKD1 geninde meydana gelen dominant mutasyonla ilişkilendirilmeye çalışımıştır. Dolayısıyla çeşitli ülkelerde prevalans çalışmaları yürütülmüştür. Türkiye'de polikistik böbrek hastalığı prevalansı en yüksek İran kedileri ve bunlarla ile akrabalığı olan kedilerde \%17,5 oranında belirlenmiştir (Bilgen ve ark., 2020). Ancak polikistik böbrek fenotipi görülmesine rağmen $P K D 1$ genindeki opal stop kodonu (UGA) oluşumuna neden olan mutasyonun belirlenmediği vakalar da bildirilmektedir (Bilgen ve ark., 2020; Guerra ve ark., 2015; Lee ve ark., 2010)

Kedi genom projesi (https://felinegenetics.missouri.edu/) Dünya'nın dört bir yanından bilim insanlarının yer aldığı bir projedir. Bu projeye katkı sağlayan araştırmalar genetik hastalıklara ve özelliklere neden olan mutasyon ve varyasyonları belirleme, kedilerin ve vahşi kedigillerin evrimini ve popülasyon dinamiklerini anlama ve kedilerimizin temel biyolojisini ve fizyolojisini anlama amaçlıdır. Bu amaçla yüzlerce kedinin tüm genom dizilemesi yapılmıs ve konsorsiyum paydaşlarına sunulmuştur.

PKHD1 geni böbrek epitel hücrelerinde siliogenesisi uyarmakta ve böbrek tubullerinin formasyonunda görev almaktadır. PKHD1 geninden kedilerde 7 transkript oluşurken insanda 2 transkript oluşmaktadır. İnsanlarda çekinik özellikte aktarılan polikistik böbrek ve hepatik hastalığı tip1'e (PKD4) neden olan mutasyonların yer aldığı PKHD1 geni, $P K D 1$ geni mutasyonunun bulunmadığı ama kistik böbrek oluşumu görülen kedilerde daha önce incelenmemiştir. Son yıllarda PKD1 mutasyonu taşımayan kistik böbrek hastası kedilerin sayısındaki artış nedeniyle PKHD1 genindeki mutasyonlar kedi genom konsorsiyumu verilerinde incelenmiş ve böbrek yetmezliği başlangıcı olan bir kedide tüm genom düzeyinde mutasyonlar taranmıştır.

\section{Materyal ve Metot}

Kedi genomu konsorsiyumu veri setinin içinden akraba olmayan 100 adet kedi genomu rastgele seçilmiş ve PKHD1 geninin bulunduğu B2 kromozomu 52,014,306-52,506,473 aralığındaki varyasyonlar filtrelenmiştir. Ayrıca tüm genom dizilemesi yapılmış ve daha önce yayınlanan polikistik böbrek hastalığına neden olan genlerin taraması (Bilgen ve ark., 2020) kapsamında PKHD1 geninde homozigot mutasyonlar belirlenmiş olan erkek kedinin böbrek fonksiyon testleri yapılmıştır. $\mathrm{Bu}$ testler kastrasyon amacıyla kliniğe getirilmesi nedeniyle uygulanmıştır. Yapılan incelemede kan böbrek değerleri yüksek olarak ölçülmüştür. Çalışmada kullanılan veriler etik izne tabi değildir, bu çalışma için invaziv bir yöntemle örnekleme yapılmamıştır.
Varyantların filtrelenmesi: Kedi genom konsorsiyumu sekans verisinin işlenmesi, varyantların çağrılması ile ilgili yapılan çalışmalar Yu ve ark. (2020) ile Buckley ve ark. (2020)'nın çalışmalarında özetlenmiştir. Bu veri setinden elde edilen kodlanan bölgelerin bulunduğu Varyant dosyası (vcf) VarSeq (Golden Helix, Bozeman, MT) programı ile incelenmiştir. VarSeq ile vcf dosyası Ensembl 101 (20 Ağustos 2020) gen anotasyonu bilgilerine göre genlerin lokasyonları ve ekzon bilgileri atanmıştır. Ardından Ensembl veri tabanına vcf formatında Varyant Etki Tahmini aracına girilmiştir (McLaren ve ark., 2016). Ardından PKHD1 geninde yüksek etkiye sahip olan varyantlar filtrelenmiş ve belirlenen varyantların in-slico fonksiyon analizleri yapılmıştır.

SIFT analizi: Varyantların tolerans edilme durumuna göre sıralamaya yarayan SIFT (Sorting Intolerant From Tolerant) skorlaması kullanılmıştır. SIFT, tolerans edilmeyen amino asit değişimlerini toleranslılardan ayıran ve bir proteindeki amino asit değişiminin fenotipik bir etkiye sahip olup olmayacağını dizi homolojisine göre tahmin eden bir araçtır (Sim ve ark., 2012). SIFT türler arasında proteinin farklılaşması ve fonksiyonunun da bununla ilişkili olarak değişmesi ilkesi ile çalışır. Buna göre fonksiyon için önemli konumlar, protein ailesinde korunmalıdır, önemsiz konumlarda ise dizilimde çeşitlilik görülebilmelidir. PKHD1 geninde belirlenen varyasyonlardan SIFT değeri önemli olanlar incelenmiş farklı türlerde amino asit dizileri karşılaştırılmıştır.

\section{Bulgular}

PKHD1 geninde Y46H, S1811Y ve V3845I varyantlarını taşıyan siyam ırkı erkek üç yaşıı kedinin üre, kan üre azotu (Blood Urea Nitrogen, BUN), kreatinin ve Glutamat Piruvat Transaminaz (Glutamate Pyruvate Transaminase, GPT) değerleri iki-iki buçuk kat yüksek olarak ölçülmüştür.

B2 kromozomu 52,014,306-52,506,473 aralığında bulunan PKHD1 geninde kodlanan ve kodlanmayan bölgeler dahil, toplamda 19,762 adet varyant belirlenmiştir. Bu varyantlar Ensembl veri tabanına yüklendiğinde 3,644 varyant filtrelenmiş ve 16,118 varyant kalmıştır. Varyantların \%98'lik kısımı intron bölgelerde bulunmaktadır. Kodlanan kısımda kalan \%2'lik varyantların ise \%86'sı sinonim olduğu için protein düzeyinde bir etkiye sahip olmadığı, ancak \%3'lük kısmının önemli etkiye sahip olduğu görülmüştür (Şekil 1). Tüm filtrelemeler sonrasında önemli etkisi olan 4 tane varyant belirlenmiştir (Tablo 1).

Belirlenen varyantların popülasyon düzeyinde incelendiğinde görülme sıklığı sırasıyla 0.003, 0.001, 0.001 ve 0.003 olduğu görülmüştür. Bu genin 


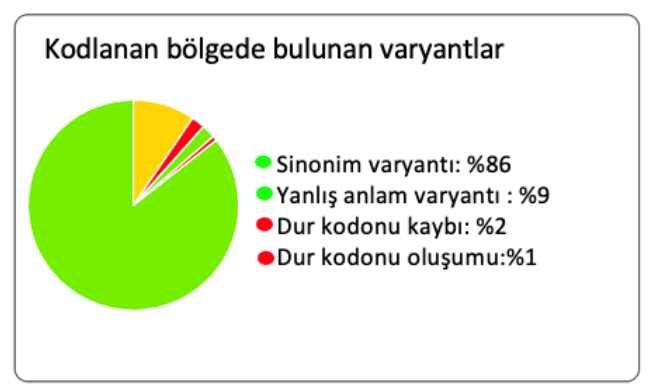

Şekil 1. Kedi PKHD1 geni Kodlanan bölgede bulunan mutasyonların dağılımı. incelenmesine neden olan kronik böbrek hastası kedide ise mutasyonların belirlenen dört mutasyonun da homozigot olduğu görülmüştür. Incelenen 100 kedi genomunda bu mutasyonlardan dur kodonu kaybı ve dur kodonu oluşumu ile sonuçlanan B2: 52152361 ve B2: 52420224 pozisyonlarında bulunan nokta mutasyonları homozigot olan başka kedi belirlenmemiştir ancak bir kedide de mutasyonların heterozigot olarak taşıdığı görülmüştür.

Tablo 1. Kedi $P K H D 1$ geninde belirlenen önemli varyantların lokasyon ve mutasyon bilgisi.

\begin{tabular}{ccccccccc}
\hline $\begin{array}{c}\text { Kromozom } \\
\text { ve lokasyon }\end{array}$ & Ref. & Alt. & Sonuç & $\begin{array}{c}\text { SIFT } \\
\text { Etki }\end{array}$ & Gen & Transkiript & Mutasyon & $\begin{array}{c}\text { Aminoasit } \\
\text { dizisi }\end{array}$ \\
\hline B2_52152361 & G & T & Dur kodonu oluşumu & Yüksek & PKHD1 & ENSFCAT00000009221.6 & G/* & Gga/Tga \\
B2_52152719 & A & G & Dur kodonu kaybı & Yüksek & PKHD1 & ENSFCAT00000009221.6 & $* / \mathrm{W}$ & $\operatorname{tgA} / \operatorname{tgG}$ \\
B2_52303121 & A & G & Dur kodonu kaybı & Yüksek & PKHD1 & ENSFCAT00000009221.6 & $* / W$ & $\operatorname{tgA} / \operatorname{tgG}$ \\
B2_52420224 & A & G & Dur kodonu kaybı & Yüksek & PKHD1 & ENSFCAT00000009221.6 & $* / W$ & $\operatorname{tgA} / \operatorname{tgG}$ \\
\hline
\end{tabular}

\section{Tartışma ve Sonuç}

Kediler de insanlar gibi kanser dahil diğer sık görülen ve nadir görülen hastalıklardan mustariptir. Bu hastalıklara ya da özgün karakterlerin ortaya çıkmasına neden olan genetik alt yapının ortaya konulması amacıyla genom düzeyindeki çalışmalar kedi genom konsorsiyumu çatısı altında son yıllarda hız kazanmaya başlamıştır. Konsorsiyum çalışmaları sayesinde kedilerde cücelik (Lyons ve ark., 2019), kardiyomiyopati (Ontiveros ve ark., 2019), otozomal dominant siliopati (Cogne ve ark., 2020) gibi belirgin karakterler ve fenotiplerin genetik alt yapısı belirlenmiştir.

Insanlarda görülen otozomal resesif polikistik böbrek hastalığı (Autosomal recessive polycystic kidney disease, ARPKD) nadir genetik hastalıklar arasında yer almaktadır. Insanlarda ARPKD'ye neden olan iki tane gen bulunmaktadır ve bu genlerde 300'den fazla mutasyon tanımlanmıştır (Hunt ve ark., 2018). Kedilerde sebebi bilinmeyen böbrek hastalıkları sıklıkla görülmektedir. Böbrek hastalıklarından kistik böbrek hastalığı genellikle $P K D 1$ genindeki mutasyon ile ortaya çıkmaktadır ancak nadiren de olsa PKD1 geni mutasyonundan bağımsız kistik böbrek hastalıkları görülmektedir. Nadir görülen ve aile bilgisi olmayan sporadik durumlarda genetik ilişkilendirme çalışması gerçekleştirmek zor olmaktadır. Evcil hayvanların kayıt sistemlerindeki gelişmeler, güncel teknolojiler ile genom dizileme fiyatlarında zaman içerisinde gerçekleşen düşüş ile bu zorlukların aşılabileceği düşünülmektedir.

PKHD1 geninde belirlenen mutasyonların görülme sıklığının düşük olması nedeniyle bu gen mutasyonu kaynaklı PKD hastalıklarının kediler için de nadir hastalıklar grubunda değerlendirilmesi gerektirmektedir. Belirlenen varyasyonların 3 tanesinin dur kodonu oluşumu ve 1 tanesinin dur kodonu kaybı olduğu görülmektedir. Güncel kedi genomunda belirlenen ve Ensembl VEP tabanında analiz edilen 128,844 ekzonik varyasyonun 838 tanesinin dur kodonu oluşumu ile 104 tanesinin ise dur kodonu kaybı ile sonuçlandığı bildirilmiştir (Buckly ve ark., 2020b). Insanlarda nadir görülen dur kodonu oluşumu ve dur kodonu kaybı mutasyonlarının türlerin adaptasyonu ve oluşumunda önemleri vurgulanmıştır (Monroe ve ark., 2021). PKHD1 geni ekzonik varyasyonlar içinde \%3'lük payı temsil eden dur kodonu oluşumu ve dur kodonu kaybı mutasyonları kedi genomu ile kıyaslandığında oransal yüksektir. Kronik Böbrek Hastalıklarının kedilerde görülme sıklığı özellikle İran ırkı ve İran kedileri ile akrabalığı olan kedilerde yüksekken (Chen ve ark., 2020) diğer ırklar ve melez kedilerde nadiren ortaya çıkmaktadır. $\mathrm{Bu}$ göz önünde bulundurulduğunda belirlenen mutasyonların frekanslarının 0,001-0,003 nadir hastalık durumunu desteklediği düşündürmektedir.

Kedilerde PKHD1 geninde belirlenen 19,762 varyant VEP aracına yüklendiğinde 3,644 varyant filtrelenmiştir. Varyant filtreleme algoritmaları kullanılan programlar arasında değişkenlik gösterebilmektedir. Yaklaşık 3,600 varyantın filtrelenmesi bu varyantların birden fazla konuma eşlenmesi durumunda, belirlenen allelin referans genomda bulunan allellerden farklı olması örneğin referans allel $A / T$ iken belirlenen allelin $G / C$ olması durumunda, bildirilen allel uzunluğundan farklı bir indel varyasyonu olması durumunda varyant 
başarısız olarak işaretlenmekte ve filtrelenmektedir. Veri seti incelendiğinde işaretlenip filtrelenen 3,644 varyantın bahsedilen sebeplerden dolayı başarısız olarak işaretlendiği anlaşılmıştır. Ancak filtrelenen varyantların intron bölgelerine dağılmış olmasından dolayı protein düzeyinde etkisi olmayacağı düşünülmüştür.

PKHD1 geninden insanlarda iki tane transkript oluşurken kedilerde 7 tane transkript tanımlanmıştır. Bu transkriptlerden insanda 4074 amino asit kodlayan ENST00000371117.8 transkripti ile kedide 4078 amino asit kodlayan ENSFCAT00000009221.6 transkriptler arası benzerlik oranı \%80'dir (Hunt ve ark., 2018). Belirlenen varyasyonların amino asit rezidüleri değişimi ve insan genomunda belirlenen varyantların etkisi karşılaştırıldığında özellikle B2 52420224 pozisyonunda yer alan varyantında SIFT skorunun insan genomu karşılığının da yüksek olduğu görülmüştür (McLaren ve ark., 2016). Bu durum ilgili amino asitlerin protein için korunmuş bölgede yer aldığını düşündürmüştür.

Kedilerde sebebi bilinmeyen ve PKD1 ilişkili olmayan kistik böbrek hastalıkları için insanlarda böbrek hastalıkları ile ilişkilendirilmiş araştırmalardan yola çıkarak aday genler tahmin edilebilir. Bu nedenle PKHD1 geninde belirlenen ve fonksiyon kaybı, dur kodonu oluşumu kaybı, dur kodonu kazanımı gibi SIFT skoru yüsek mutasyonlar göz ardı edilmemeli ve PKD1 mutasyonu olmayan ancak polikistik böbrek fenotipi görülen kedilerde ayrıca değerlendirilmelidir.

\section{Kaynaklar}

Bilgen N, Bişkin Türkmen $M$, Çınar Kul B, Isparta S, Şen $Y$, Akkurt MY, Çıldır Ö ş, Bars Z, 2020: Prevalence of PKD1 gene mutation in cats in Turkey and pathogenesis of feline polycystic kidney disease. J Vet Diagn Invest, 32 (4), 549-555.

Buckley RM, Gandolfi B, Creighton EK, Pyne CA, Bouhan DM, LeRoy ML, Senter DA, Gobble JR, Abitbol M, Lyons LA, 99 Lives Consortium, 2020a: Werewolf, There Wolf: Variants in Hairless Associated with Hypotrichia and Roaning in the Lykoi Cat Breed. Genes (Basel) 11 (6), 682.

Buckley RM, Davis BW, Brashear WA, Farias FHG, Kuroki K, Graves T, Hiller WL, Kremitzki M, Li G, Middleton RP, Minx P, Tomlinson C, Lyons LA, Murphy WJ, Warren WC, 2020b: A new domestic cat genome assembly based on long sequence reads empowers feline genomic medicine and identifies a novel gene for dwarfism. PLoS Genet, 16(10).

Chen $H$, Dunaevich A, Apfelbaum N, Kuzi S, Mazaki-Tovi M, Aroch I, Segev G, 2020: Acute on chronic kidney disease in cats: Etiology, clinical and clinicopathologic findings, prognostic markers, and outcome. J Vet Inter Med, 34 (4), 1496-1506.

Cogne B, Latypova X, Senaratne LDS, Martin L, Koboldt DC, Kellaris G, Fievet L, Le Meur G, Caldari D, Debray D, Nizon M, Frengen E, Bowne S, 2020: Mutations in the kinesin-2 motor kif3b cause an autosomaldominant ciliopathy. Am J Hum Genet, 106 (6), 893904.

Gardner Jr KD, 1988: Cystic kidneys. Kidney Int, 33 (2), 610-621.

Guerra JM, Daniel AGT, Cardoso NC, Grandi F, Queiroga F, Cogliati B, 2015: Congenital hepatic fibrosis and polycystic kidney disease not linked to C> A mutation in exon 29 of PKD1 in a Persian cat. JFMS open reports, 1(2), 2055116915619191.

Hunt SE, McLaren W, Gil L, Thormann A, Schuilenburg H, Sheppard D, Parton A, Armean IM, Trevanion SJ, Flicek P, Cunningham F, 2018: Ensembl variation resources. Database, 2018(2018) bay119.

Lee YJ, Chen HY, Hsu WL, Ou CM, Wong ML, 2010: Diagnosis of feline polycystic kidney disease by a combination of ultrasonographic examination and PKD1 gene analysis. Vet Rec, 167 (16), 614-618.

Lyons LA, Fox DB, Chesney KL, Britt LG, Buckley RM, Coates JR, Gandolfi B, Grahn RA, Hamilton MJ, Middleton JR, Sellers ST, Villani NA, Pfleuger S, 99 Lives Consortium, 2019: Localization of a feline autosomal dominant dwarfism locus: A novel model of chondrodysplasia. bioRxiv. 687210.

Lyons LA, Biller DS, Erdman CA, Lipinski MJ, Young AE, Roe BA, Qin B, Grahn RA, 2004: Feline polycystic kidney disease mutation identified in PKD1. J Am Soc Nephrol, 15(10), 2548-2555.

McLaren W, Gil L, Hunt SE, Riat HS, Ritchie GR, Thormann A, Flicek P, Cunningham F, 2016: The Ensembl Variant Effect Predictor. Genome Biol, 6, 17(1), 122.

Monroe JG, McKay JK, Weigel D, Flood PJ, 2021: The population genomics of adaptive loss of function. Heredity, 126 (3), 383-395.

Ontiveros ES, Ueda Y, Harris SP, Stern JA, 99 Lives Consortium, 2019: Precision medicine validation: Identifying the mybpc3 a31p variant with wholegenome sequencing in two maine coon cats with hypertrophic cardiomyopathy. J Feline Med Surg 21 (12), 1086-1093.

Sim NL, Kumar P, Hu J, Henikoff S, Schneider G, Ng PC, 2012: SIFT web server: predicting effects of amino acid substitutions on proteins. Nucleic Acids Res., 40(W1), W452-W457.

Yu Y, Creighton EK, Buckley RM, Lyons LA, 99 Lives Consortium, 2020: A Deletion in GDF7 is Associated with a Heritable Forebrain Commissural Malformation Concurrent with Ventriculomegaly and Interhemispheric Cysts in Cats. Genes (Basel), 11(6), 672.

${ }^{*}$ Yazışma Adresi: Nüket BíLGEN

Ankara Üniversitesi, Veteriner Fakültesi, Genetik Anabilim Dalı, Ankara, Türkiye.

e-mail: nbilgen@ankara.edu.tr 